\title{
Approach to the methodology for assessing and typologizing excursion objects within the framework of the experience economy concept (on the example of castles in Kaliningrad region)
}

\author{
A. V. Mitrofanova, A. Yu. Anokhin, and V.A. Khilsher \\ Immanuel Kant Baltic Federal University
}

\begin{abstract}
Currently, there are many approaches to assessing the competitiveness of tourist sites. However, these approaches mainly consider individual factors, such as the availability of a tourist facility, its safety, content, marketing and many others. In this study, the authors drew attention not to individual factors, but to the final result of the activities of tourist facilities, the competitiveness of which is ensured by the formation of impressions after visiting them. Within the framework of the concept "Economy of impressions", a methodology for assessing the tourist attractiveness of excursion objects is proposed, an approach to the typology of objects is presented in order to develop an effective development strategy and determine the prospects for their use for tourism purposes. Approbation of the methodology for assessing and typologizing excursion objects was carried out on the example of castle structures in the Kaliningrad region.
\end{abstract}

\section{Introduction}

Currently, there are many scientific works in the field of socio-cultural services and tourism, dedicated to the study of significance of tourist display objects for the development of tourism in the studied territory. Such studies include geographical, economic, psychological, and other aspects. This is due to a comprehensive approach to the development and competitiveness of the tourist object in order to include it in the regional tourist potential. One of the most significant problems in the field of tourist and excursion use of castle objects in Kaliningrad region, is their poor preservation, loss of individual elements or appearance as a whole. The problem of the loss of objects of historical and cultural heritage in recent history is one of the most significant [12]. Its relevance for Kaliningrad region can be illustrated by the example of the key castle - Königsberg, lost in the 20th century. This is what makes it relevant to design models for the functioning of ruined castle structures as tourist objects.

\section{Materials and methods}


The study of competitiveness of tourist complexes, objects of sightseeing object is dedicated to the work of T. Levchenko, E. Koryagina, T. Levchenko, E. Koryagina, T. Shabalina, O. Lebedeva "A Project-Based Approach to Ensuring the Competitiveness of a Region's Tourism-Recreation Complex" [17], "Methodological approaches to the assessment of historical and cultural resources in tourist destinations" A. Fedulin, O. Lebedeva, L. Dukhovnaya, S. Ilkevich [13], R. Harrill, \& T Potts,.D. (2003) [14], S. Plog [16], M. Monford [15].

These works draw attention to the fact that the objects of cultural heritage is not fully, not effectively used in regional tourism. The competitiveness of these objects depends on such factors as their condition, effective management by the users or owners of the objects, participation and organization of an active advertising campaign, cooperation with information centers and travel companies in the region.

The application of the "Experience economy" concept, first described by J. Gilmore, J. Pine [5], Is important in Today's realities. The study of this topic in the field of tourism was carried out by A.Yu. Alexandrova [1]., O.E. Afanasiev [4], N.V. Novichok [10], N.A. Kolodiy [8], L.P. Voronkova [6] and many other authors. The concept of the economy of impressions is considered such aspects as: the organization of new forms of tourism and excursion programs that include the active participation of tourists and sightseers themselves, the introduction of innovative forms of organizing and conducting tourist programs, the inclusion of interactive methods of excursions. In accordance with the experience economy concept, it is not enough to organize a passive examination for the effective use of the sightseeing objects, museum objects, it is necessary to develop programs that allow the tourist to be included in the excursion process, to become an active participant in it.

Tourist regions attract tourists with their diversity and how they differ from the permanent place of tourist residence. D.V. Nikolaenko [9] describes this feature, which is determined by human mentality, as well as nation, perception of permanent environment, psychological need for a temporary change in landscape and other homeland components. In Kaliningrad region of the Russian Federation, cultural and educational tourism is one of the main types of tourism in the region. This is due to the rich history of the region, including various periods and historical strata. Most tourists associate Kaliningrad region with the opportunity to travel to the past and immerse in the atmosphere of the former East Prussia. On the region territory, 19 castles have been preserved, they are in different conditions, most of which are included in the routes of excursions in the region. However, most of the remaining objects are in a ruined state. Another peculiarity of castles in Kaliningrad region is a significant rebuilding in the 16-18th centuries, the loss of the castle status and adaptation to prisons or administrative buildings. In this regard, even castles classified as "preserved" have largely lost the features of castle architecture. The use of castle objects is of great international importance, these objects are included in the crossborder tourist route "Through the Gothic castles".

The competitiveness of each castle object depends on different factors: object usage efficiency, carrying out by the owner or user of anti-abatement, conservation works, filling the object, use of interactive forms of displaying the object, the organization of newsworthy events, and much more. In order to determine the tourist potential of this category of tourist attractions a sociological study was performed. The article points out that the competitiveness and impression, the tourist's satisfaction with the received excursion service, is influenced by the tour guide. Currently, in the scientific literature, there are works dedicated to the study of the importance of guide's personality in tourist product implementation [7]. The tour guide not only provides excursion service, he is an intermediary between the consumer and the sightseeing object, guiding the perception of sightseers, allowing them to perceive and interpret the sightseeing objects and their 
How often do you visit castles with tourists?

36 answers
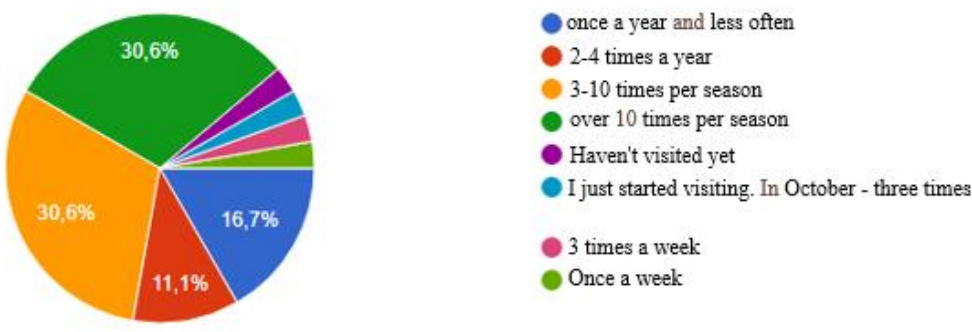

Fig. 2. Frequency of visits to the castle objects of Kaliningrad region by tourists.

The question about how often tour guides come together with tourists to the castles of Kaliningrad region showed that these objects do have a high tourist potential and are in stable demand among tourists in the region (Figure 2). These castle sightseeing objects are popular with both individual tourists and group tourists. Among the group tourists, there are school groups, groups of tourists that are collected on excursions by tour operators located in Kaliningrad, Zelenogradsk and Svetlogorsk. Individual tourists visit the castles as part of individual excursions by car with a guide, as it is not always possible to get to the castles independently. However, visiting the castle objects as part of an organized tour individually or in groups provides the value of sightseeing and affects the final impression of the tourist from visiting castles.

Which of the options for sightseeing of these castles is preferable for you?

Choose no more than 2 possible answers

36 answers

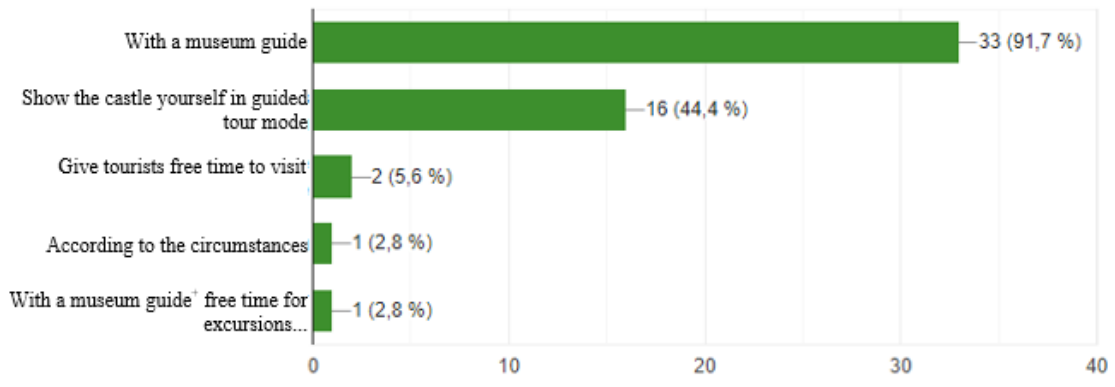

Fig. 3. Priority forms of conducting excursion programs in castles.

Tourist programs often involve several guides: a guide who accompanies the group during the trip, as well as guides who work on the sightseeing objects. In this regard, the next question concerned what organizational form of castle demonstration guides choose in their programs, that is, which of the forms is more convenient for them. There were two possible answers to this question. Most of the guides chose the option of organizing a tourist program and cooperation with a tour guide, representing each castle independently, working at a separate object. This option was preferred by 33 out of 36 respondents half of the respondents, 16 out of 36 preferred to "show the castle on their own during the tour", 
two people prefer to give their free time to the excursionists, one respondent is guided by circumstances and one decided to combine a museum guide and free time tour of the castle by excursionists.

These answers allow to make a conclusion that creation a takeaway from the tour, making it more intense, interesting, allows to combine in one tourist program tour guides accompanying tourists on the bus and tour guides working directly on the demonstration object. "Museum guides" use more diverse forms of information presentation, interactive methods of involving the tourist in the cognitive process, his immersion in the sociocultural, scientific, interactive environment.

An important objective of this study was the expert assessment of the quality of excursion services provided by the castle objects. To determine this indicator, the cost equivalent of the tourist's impressions of visiting this castle was determined. The study showed that at present the value assessment of the quality of provided excursion services, which is eventually evaluated by the impression that the excursionist received during the castle tours, does not always correspond to the current visit cost. In this case, depending on the format of castle economic activity, the diversification of provided services, there may be deviations in one direction or the other. Figure 4 shows a comparison of the financial assessment of visitors ' impressions and the cost of a standard adult ticket. As can be seen from Figure 4, the cost of visiting castles Brandenburg, Insterburg and Waldau is lower than the expected impressions. At the same time, the cost of visiting Insterburg Castle for individual tourists (without providing a museum guide) is not charged and is replaced by a charitable contribution. The castles Schaaken and Ragnit operate under a standard economic model and the ticket price is slightly higher than the expected impressions. A visit to the part of Waldau Castle rented by the Sorokin family more than doubles the expected effect.

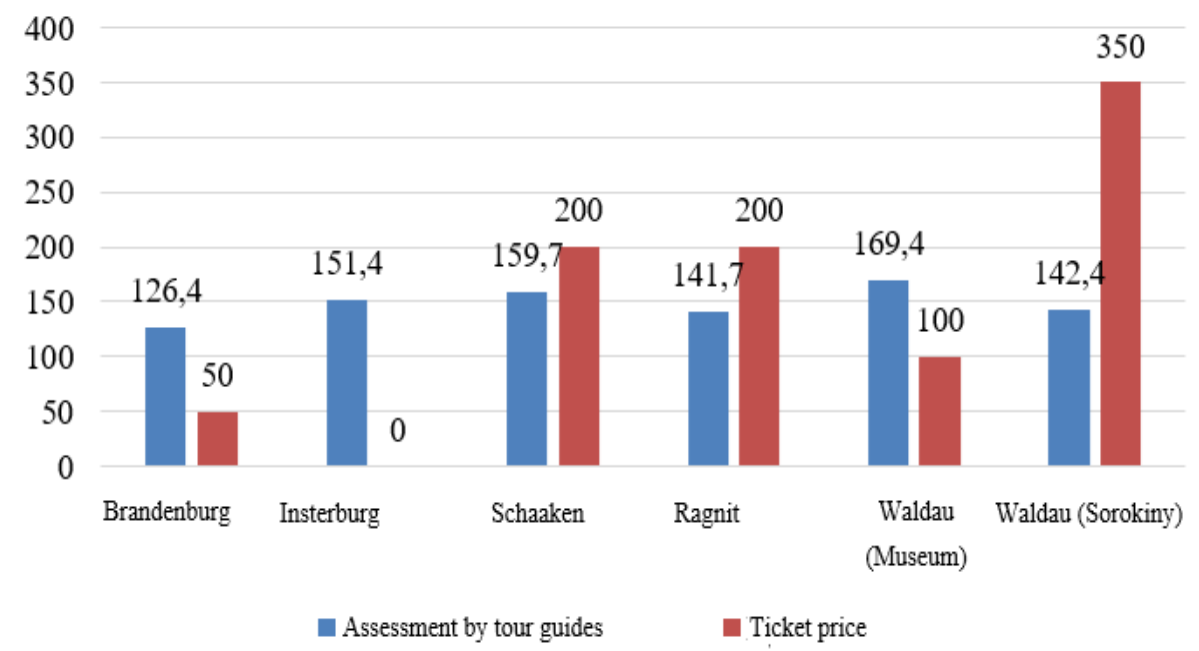

Fig. 4. Assessment by tour guides of the value of visiting castles in Kaliningrad region of the Russian Federation.

The maximum rating in terms of the use of castle buildings in Kaliningrad region for tourism purposes received a castle Valdau, Schaaken Castle and Insterburg Castle. Interesting for the study is to identify the criteria for assessing the value of these objects in the field of tourism. To study the tourist attractiveness of castles and the prospects for their use as tourist attractions, we formulated the basic criteria for assessing the value of the object usage for tourist purposes. 
1. Aesthetic object characteristics. This parameter is self-sufficient and in some cases quite significant. Taking into account the ruined state of most of the castles in the region, unprepared tourists are disappointed by the discrepancy between expectations and actual appearance of the object.

2. Assessment of historical and cultural heritage (historical and cultural content). The main cognitive value of the regional castles is not in the external appearance, but in the rich and eventful history of the castle. It is this content that was assessed in this parameter.

3. Evaluation of the museum exhibition (filling the object). Individual castles exist not only as art spaces, but also have a museum exposition. Related to the history of the castle or surrounding areas artifacts, cultural objects and everyday life are collected and arranged in a museum exhibition, which allows to conduct full guided tours.

4. Diversification of the tourist offer (holding event and interactive events). Considering the low-key aesthetics of castles as such, both permanent forms of animation and interaction as well as major festival events held in castles are becoming increasingly important in the region. The use of such forms of work with visitors significantly increases the impression volume and variety.

5. Assessment of work and cooperation with users, owners and employees of the object. Given the fact that, due to their small preservation, castles are not capable of making an impression on their own, the teams that deal with the castles, the maintenance of the grounds, the landscaping, the decoration of the interiors, and the interaction between the castle and the visitor are of great importance. They also play an important role when interacting with tour organizers - travel agencies or individual guides.

These assessment criteria were highlighted as the main, according to them was analyzed each castle object, which is visited by tourists.

Table 1. Average values of indicators for all castles

\begin{tabular}{|l|r|}
\hline \multicolumn{1}{|c|}{ Parameter } & Average value \\
\hline Aesthetic characteristics & 3.492 \\
\hline Historical and cultural content & 3.927 \\
\hline Museum exhibition & 3.249 \\
\hline Interactive events and newsworthy events & 3.611 \\
\hline Organization's team & 3.709 \\
\hline
\end{tabular}

As follows from Table 1, the most significant factor in creating impressions is their historical and cultural potential - 3,927 points on a 5-point scale. In second place with a slight margin - the team of the organization, and in the third - interactive and newsworthy events. The totality of these parameters confirms that the main technology of formation of tourist experience in these objects is related to their "life" - that is, the dynamics, opportunities to engage visitors in active perception, interactive forms of familiarity with the object. 4th place was for the parameter of aesthetics, very different from one object to another, and only in the last place - the presence of a museum exhibit.

Table 2. Values of indicators for individual castles

\begin{tabular}{|l|r|r|r|r|r|r|}
\hline Parameter/castle & Brandenburg & Insterburg & Schaaken & Ragnit & $\begin{array}{l}\text { Waldau } \\
\text { (Museum) }\end{array}$ & $\begin{array}{l}\text { Waldau } \\
\text { (Sorokiny) }\end{array}$ \\
\hline Aesthetic characteristics & 2.667 & 3.444 & 3.389 & 3.625 & 4.056 & 3.771 \\
\hline $\begin{array}{l}\text { Historical and cultural } \\
\text { content }\end{array}$ & 3.529 & 4.139 & 4.0 & 3.968 & 4.25 & 3.676 \\
\hline Museum exhibition & 2.357 & 3.471 & 3.686 & 2.609 & 4.286 & 3.091 \\
\hline $\begin{array}{l}\text { Interactive events and } \\
\text { newsworthy events }\end{array}$ & 3.0 & 3.969 & 4.171 & 3.0 & 3.968 & 3.563 \\
\hline Organization's team & 2.727 & 4.059 & 3.971 & 3.773 & 4.314 & 3.412 \\
\hline
\end{tabular}


The average values of each castle in total for all five indicators show the leading position of the museum "Waldava Castle" -4.17 , the second and third places are shared by Schaaken (3.84) and Insterburg - (3.82). At the same time, each of the castles has a "leading" indicator, which is determined by the castle strategy and is its competitive advantage. Brandenburg, Insterburg and Ragnit have historical and cultural content, Waldau (Sorokiny) - aesthetic characteristics, Waldau-museum exposition, and Schaaken newsworthy events and interactive events.

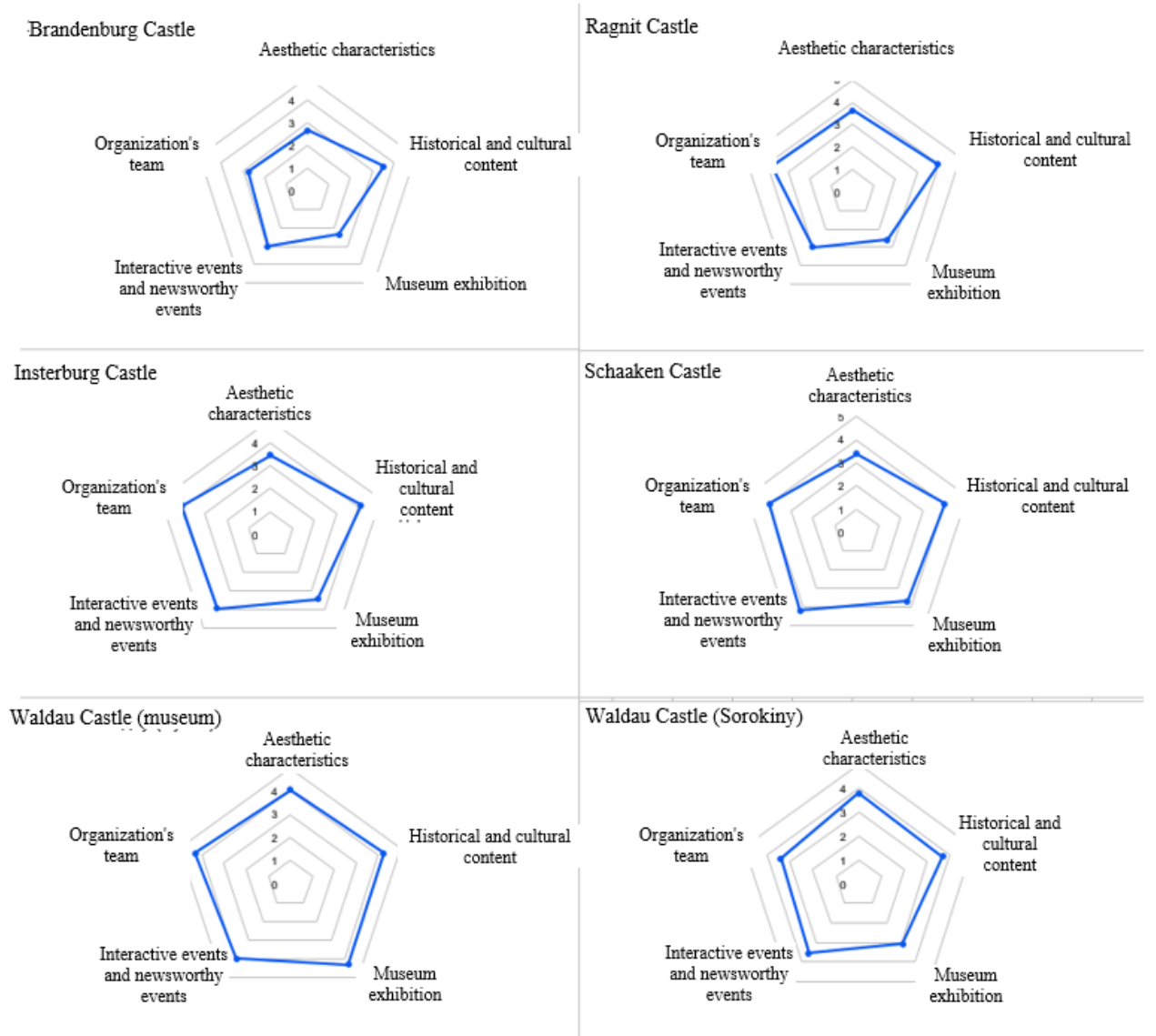

Fig. 5. Component assessment of value of visiting the castles of Kaliningrad region 


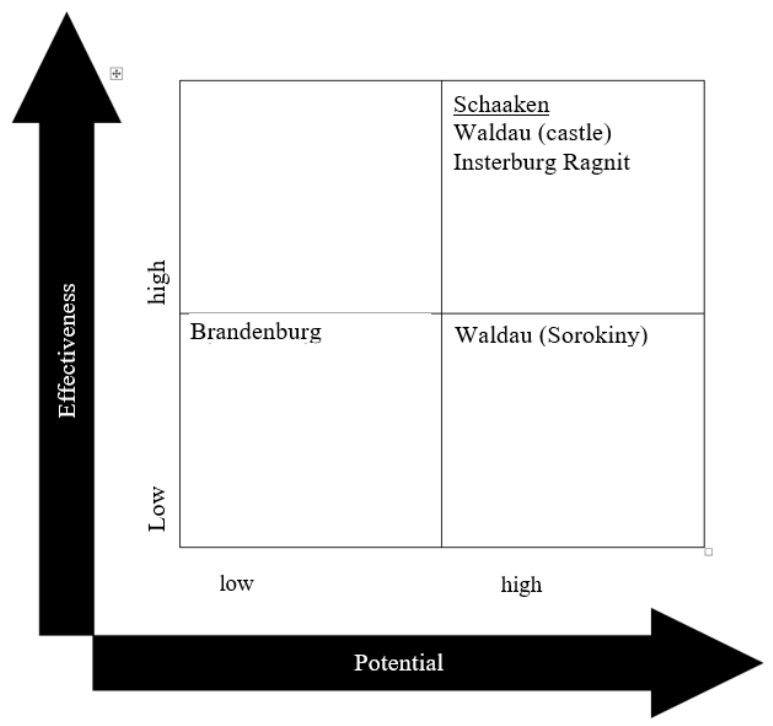

Fig. 6. Effectiveness matrix of the castle objects (compiled by the authors).

Based on the results of the evaluation of tourist attractiveness of castles and the prospects for their use as tourist attractions, the authors proposed the following typology of objects:

1. Castle objects that have a low potential for development, which currently does not allow them to achieve high efficiency (Brandenburg Castle). The optimal strategy for such castles is to create activities, including theatrical and interactive forms of leisure organization, less tied to the preservation and restoration of the castle object.

2. Objects that have a high potential, but do not realize it for a number of reasons. According to our study, such objects include the Waldau Castle (Sorokiny family). The high cost of visiting, the lack of focus on the mass tourist does not allow to become a strong center of attraction. The best strategy for such objects can be the development of in-demand forms of tourist activities, their active promotion in the tourist market, as well as cooperation with travel agencies and individual guides, generating a stable tourist flow.

3. Castle objects actively used in tourism activities and emphasizing the tourism specificity of the region (Schaaken Castle, Insterburg Castle, Ragnit Castle and the museum "Valdav Castle"). These objects have a high historical and cultural potential, and are also characterized by an average or high preservation of the castle object. The active implementation of events already ensures a high level of effectiveness. The optimal strategy for these objects is partial or complete restoration of the original appearance or some authentic castle elements, the creation in the castle premises of museum exhibitions, restaurants, cafes and hotels.

The first group of objects is currently used in the organization and conduct of thematic tours and their quick inspection, while the third category of objects is a separate center of attraction for tourists. Tourists come to these objects not only as part of thematic tours, but also to participate in the event, integrative activities that can take from one to several days. Schaaken Castle, Instenburg Castle and Waldau Castle are actively engaged in the tourism business. The castles Schaaken (Instenburg) attracts tourists with its interactive and event activities, Waldau Castle has an interesting exhibition and hosts large groups of schoolchildren.

Until recently, Schaaken Castle was part of the second group of objects. The situation was changed by the organization and holding of an newsworthy event on the castle 
territory, a theatrical musical production in the walls of the castle "Peer Gynt". The directors of the tourist experience were several tour operators of Kaliningrad region, who organized the cooperation between the Kaliningrad Symphony Orchestra, the theater of plastics "Shkaf" and implemented the project "Classics in the ancient walls" of Schaaken Castle. This event has no analogues in Russia, in 2019 it received the Grand Prix of the National Award Russian Event Awards, entered the National Calendar of Events EventsRussia.com and in the Top 200 best events in Russia in 2020. This example clearly demonstrates the effectiveness of the experience economy concept. It's not the object itself and its walls that are interesting, but its contents. Most guides believe that it is not the aesthetic condition of the object, but its effective use by the owners and users of the castles that determine the competitiveness of the site. Different concepts and strategies for using castles for tourist purposes can be chosen, but the main thing is to create a tourist impression from its use, which becomes possible only if the tourist is actively included in the program, holding newsworthy events, master classes, theater performances, quests and other types of interactive programs as elements of the impression economy.

\section{Conclusion}

Interpretation of the sociological survey of tour guides in Kaliningrad region to assess the tourist value of castle objects in the region allows to draw several conclusions. First, the tour guide is one of the most important factors in competitiveness of the sightseeing objects. From professional experience, personal qualities, communication psychology skills, knowledge and ability to apply innovative methods of excursions depends on the tourist's impression of the received tourist service, and therefore depends on competitiveness of the sightseeing object. Secondly, the tourist value of visiting the castle object, as well as other sightseeing objects, directly depends on application of the concept "The Experience Economy". To ensure the competitiveness of tourist programs, representatives of the tourism business, users or owners of the sightseeing objects become directors and creators of excursion experience, tourism becomes a creative industry. In order to create an impression of the tourist product in the programs tour operators are trying to involve different senses: smell, taste, emotional and auditory perception. In this regard, among the factors that affect the emotional assessment of tourists visiting the castles of Kaliningrad region, such criteria as the aesthetic characteristics of the object, the historical and cultural content, the museum exposition (filling the object with sound, taste, visual, tactile impressions), the diversification or diversity of the tourist offer (holding event and interactive events), as well as cooperation with users, owners and employees of the object (the collective of the organization) were highlighted. Castles that use these criteria together are more competitive. The maximum positive emotional response is received by excursion programs built on the use of the concept "The Experience Economy" and attracting experienced creative guides who use modern and interactive methods in their work, providing modern requests of different target tourist audiences. The selected criteria for assessing the tourist attractiveness of castles, presented in the study on their basis, the typology of tourist attractions in terms of prospects for use and strategies to improve competitiveness, can be adapted and extrapolated to the study of other types of sightseeing objects.

\section{References}

1. A. Yu. Alexandrova, Service in Russia and abroad, 13.3(85), 6 (2019) 
2. A. Yu. Anokhin, Innovations in excursion work: concepts, technologies, practice, 228 (Moscow-Berlin, 2020)

3. A. M. Astanskaya, Proceedings of the St. Petersburg State University of Culture and Arts., 206, 121 (2015)

4. O. E. Afanasiev, A. V. Afanasieva, Modern problems of service and tourism, 13(2), 7 (2019)

5. B. Joseph, I. I. Pine, J. H. Gilmore, The experience economy. Work is theater \& every business a stage, 304 (M.: "Williams", 2005)

6. L. P. Voronkova, Economics and management: problems, solutions, 2(2), 10 (2017)

7. O. E. Afanasiev, Innovations in excursion work: concepts, technologies, practice, 33 (Moscow-Berlin, 2020)

8. N. A. Kolodiy, The economy of sensations and impressions in tourism and management, 326 (M.: Yurayt, 2018)

9. D. V. Nikolaenko, Recreational geography, 228 (Kiev: Vlados, 2003)

10. N. V. Novikov, Service in Russia and abroad, 8(46), 113 (2013)

11. A. V. Mitrofanova, D. Yu. Zhitinevich, Innovations in excursion work: concepts, technologies, practice, 33 (Moscow-Berlin, 2020)

12. Yu. Yu. Filippov, Tourist and recreational potential and features of tourism development: materials of the international scientific and practical conference of students and postgraduates, 37 (Kaliningrad: Immanuel Kant Baltic Federal University, 2011)

13. A. A. Fedulin, L. V. Zgonnik, O. Ye. Lebedeva, L. L. Dukhovnaya, S. V. Ilkevich, Journal of Environmental Management and Tourism, 8(6), 1198 (2017)

14. R. Harrill, T. D. Potts, Journal of the American Planning Association, 69(3), 233 (2003)

15. M. Monford, Comperitividad y factores criticos de exito en la "hoteleria de litoral": experiencia de los destinos turisticos Benidorm y Peniscola (Doctoral Dissertation, Universidad de Valencia, Espanha, 2000) http://www.cervantes.com

16. S. C. Plog, Leisure Travel: Making it a Growth Market...Again! (N.Y.: Willey, 1991)

17. T. Levchenko, E. Koryagina, T. Rassokhina, N. Shabalina, O. Lebedeva, Journal of Environmental Management and Tourism, 9(8), 1706 (2019) 